\title{
Physical-chemical and mineralogical characterization of fine aggregates from construction and demolition waste recycling plants
}

\author{
Fernando Rodrigues ${ }^{a}$, Maria Teresa Carvalho ${ }^{a}$, Luís Evangelista ${ }^{\mathrm{b}}$, Jorge de Brito ${ }^{\mathrm{a}, *}$ \\ ${ }^{a}$ Department of Civil Engineering, Architecture, and Georresources, Instituto Superior Técnico, Technical University of Lisbon, Av. Rovisco Pais, \\ 1049-001 Lisbon, Portugal \\ ${ }^{\mathrm{b}}$ Department of Civil Engineering, Instituto Superior de Engenharia de Lisboa, R. Conselheiro Emídio Navarro 1, $1959-007$ Lisbon, Portugal
}

\section{A R T I C L E I N F O}

\section{Article history:}

Received 1 October 2012

Received in revised form

15 February 2013

Accepted 16 February 2013

Available online 4 March 2013

\section{Keywords}

Construction and demolition waste

Fine recycled aggregates

Physical-chemical characterization

Recycling plant

\begin{abstract}
A B S T R A C T
Construction and demolition waste (CDW) represents around 31\% of all waste produced in the European Union. It is today acknowledged that the consumption of raw materials in the construction industry is a non-sustainable activity. It is thus necessary to reduce this consumption, and the volume of CDW dumped, by using this waste as a source of raw materials for the production of recycled aggregates. One potential use of these aggregates is their incorporation in reinforced concrete as a replacement of natural aggregates. A concrete that incorporates these aggregates and still performs well requires them to be fully characterized so that their behaviour within the concrete can be predicted. Coarse recycled aggregates have been studied quite thoroughly, because they are simpler to reintroduce in the market as a by-product, and so has the performance of concrete made with them. This paper describes the main results of research designed to characterize the physical and chemical properties of fine recycled aggregates for concrete production and their relationship with mineralogical composition and preprocessing. The constraints of the incorporation of fine aggregates in reinforced concrete are discussed. It is shown that, unless a developed processing diagram is used, this application is not feasible.

(c) 2013 Elsevier Ltd. All rights reserved.
\end{abstract}

\section{Introduction}

In 2010 consumption of aggregates was $37,400 \mathrm{Mt}$ and this will increase to 48,000 Mt until 2015 (The Freedonia Group, 2012). The extraction of natural sand from river and sea beds also has a strong environmental impact. According to Austen et al. (2009) this extraction causes changes in their beds that may lead to a loss of balance between coastal sand and sea bed sand, with dire consequences for the coast. In addition to these impacts, dredging sand may also modify the biological balance. This dredging would be unnecessary if stone used to make gravel were crushed to produce sand. However, this crushing would mean an increase in energy used, leading to higher emissions of $\mathrm{CO}_{2}$, while failing to solve the problem of depleting resources through mining. To determine whether using recycled aggregates and running construction and demolition waste (CDW) recycling plants has positive or negative technological, environmental and economic impacts various studies have been presented in the literature. Tam (2009) performed an extensive field survey on Japanese and Australian construction industries and concluded that in Australia the prevailing

\footnotetext{
* Corresponding author. Tel.: +351 218443659; fax: +351 218443071.

E-mail address: jbrito@civil.ist.utl.pt (J. de Brito).
}

opinion is still that recycled aggregates are costly and have limited applications, leading the author to propose a recycling unified policy. Blengini and Garbarino (2010) studied the environmental impact of the recycling process as a whole using LCA and GIS in the northern region of Italy and found that recycled aggregates are environmentally viable and capable of performing an important role on the aggregates supply mix of the construction industry. Later, Blengini et al. (2012) defined new guidelines for the use of LCA tools for the sustainable construction and aggregates recycling, which will boost their use on construction industry. Coelho and de Brito (2012a, 2012b) studied the economic viability of Portuguese recycling plants and concluded that the return of investment can occur somewhere between 2 and 8 years, depending on the surrounding socio-economic conditions.

In order to guarantee the sustainable development of this industry the consumption of resources must be reduced and the utilization of CDW as raw materials must simultaneously be increased. CDW is presently recycled in several countries. It represents around $31 \%$ of all waste produced at the moment in the European Union (Fisher and Werge, 2009). The use of coarse recycled aggregates (CRA) in concrete production is already a valid option, since research has proved that their incorporation is viable. Rahal (2007) concluded that concrete made with coarse recycled 
aggregates (CRA) has similar mechanical properties to those of concrete made with coarse natural aggregate (CNA), up to a strength of $40 \mathrm{MPa}$, with similar behaviour regarding deformability and stress-strain peaks. Kwan et al. (2011) obtained a good correlation between water absorption and the replacement ratio of CNA by CRA. The intrinsic permeability shows linear variation with the CRA content and the differences between reference concrete and concretes made with CRA decrease as curing proceeds. Fonseca et al. (2011) and Amorim et al. (2012) studied the effect of curing conditions on the mechanical and durability properties of concrete made with coarse recycled concrete aggregates, respectively. The authors found that the different curing conditions do not seem to affect the various concretes' properties tested. Ferreira et al. (2011) studied the effect of the saturation process on mixing and concrete performances and found that the best mechanical performance was achieved when the aggregates were mixed at partially saturated moisture conditions, i.e. not pre-saturated. Vieira et al. (2011) analysed the fire behaviour of concrete made with CRA and found that the thermal behaviour and the post fire residual mechanical properties are somewhat similar, regardless of the replacement ratio used. Richardson et al. (2011) studied the freeze/thaw behaviour of concrete made with CRA and found that recycled aggregates with freeze/thaw mitigation additives can be used for applications where freezing and thawing of concrete occur.

However, the use of fine recycled aggregates (FRA), i.e. with size of less than $4 \mathrm{~mm}$, in concrete products is not yet widely accepted. There are some countries whose regulations forbid the use of FRA in concrete, namely China, Germany, Hong Kong, Portugal, Spain and UK (Gonçalves and de Brito, 2010). This limitation of FRA use is explained by the unpromising results of early research work, in particular because of high water absorption and contaminant content (Solyman, 2005; Angulo et al., 2009), properties that may create problems in both fresh and hardened state concrete (Zega and Maio, 2011). Therefore these aggregates have been used mostly in bases and sub-bases of transport infrastructure and the recovery of former quarries by landscaping.

Because of the dwindling availability of fine natural aggregates (FNA) and of locations to dump the fine fraction of CDW when it is not reused, the study of FRA has gained momentum and various researchers have obtained satisfactory results when they are used in concrete under given circumstances. Leite (2001) studied the mechanical performance of concrete made with FRA from CDW and got similar and sometimes even higher results for concrete made with recycled materials, compared to conventional concrete. On the other hand, Khatib (2005) studied the compressive strength and shrinkage of concrete made with crushed concrete and crushed brick as replacement of FNA and concluded that the use of crushed concrete could lead to a reduction of compressive strength up to $30 \%$. On the contrary, crushed brick did not seem to influence compressive strength. As for shrinkage, the author found similar trends, as mixes made with recycled crushed concrete behaved worse than those made with crushed brick. Evangelista and de Brito (2007, 2010) studied the mechanical and durability performance of FRA from concrete and concluded that compressive strength was kept at the same level regardless of the replacement ratio of FNA by FRA used. The remaining mechanical properties showed decreased performance with the increase of the replacement ratio. As for durability, the increasing presence of FRA lead to linearly correlated decreasing performance. Zega and Maio (2011) studied the effect of the presence of FRA on the mechanical and durability performance of concrete and concluded that up to $30 \%$ of replacement ratio the mechanical and durability performance met the requirements imposed by different codes for structural concrete. Pereira et al. (2012a, 2012b) studied the effect of superplasticizers on the mechanical and durability performance of concrete made with FRA

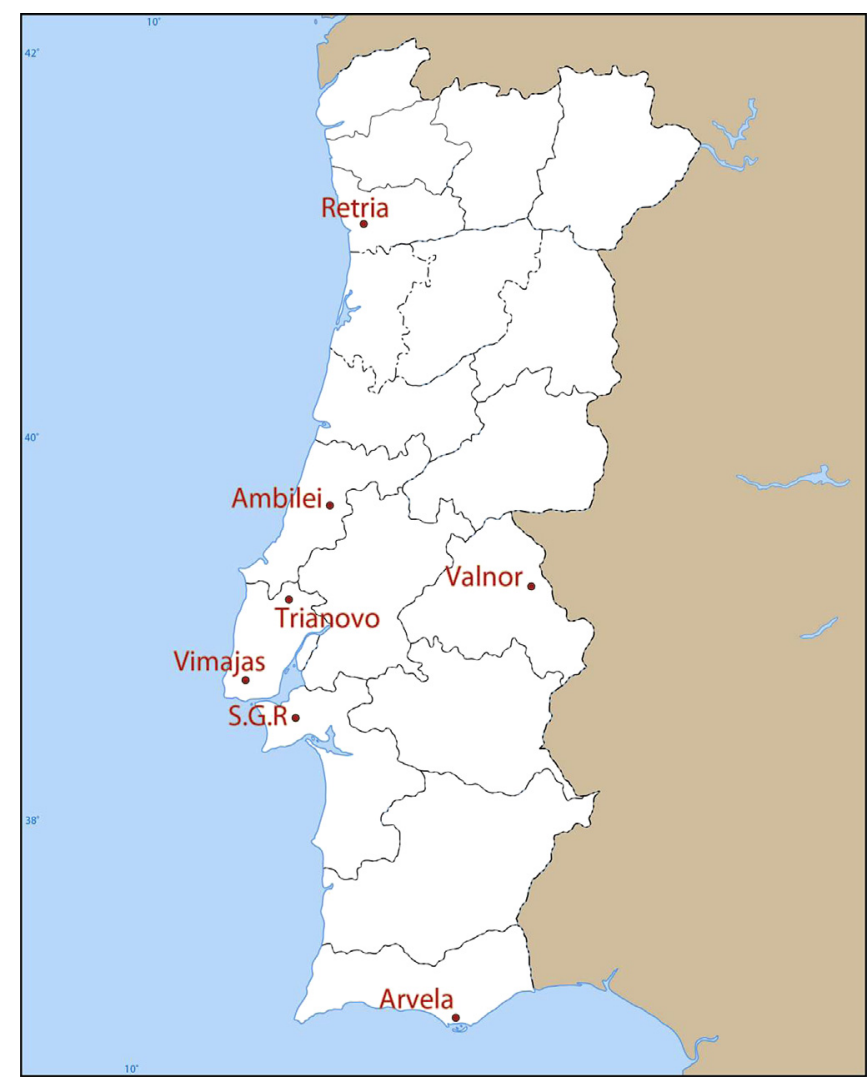

Fig. 1. Location of the plants supplying the samples.

and concluded that the presence of plasticizers had similar effects on all mixes, regardless of their replacement ratio. Also, the authors concluded that the detrimental effects of the presence of FRA on the properties studied could be easily mitigated by using a superplasticizer, in order to lower the $\mathrm{w} / \mathrm{c}$ ratio without losing workability.

The percentage of fine material (below $4 \mathrm{~mm}$ ) in CDW, the object of this research, is significant. Bianchini et al. (2005) studied different samples and obtained a range from $12 \%$ to $60 \%$. This fully justifies the study and use of this fraction as raw material in other products such as concrete.

The use of FRA in reinforced concrete presupposes knowing the relevant physical-chemical properties. These are directly related to the mineralogical composition of the CDW from which the recycled aggregates came (Rodrigues et al., 2011). Considering that the plants that recycle CDW collect them locally it is to be expected that the FRA composition also depends on their geographical location

Table 1

CDW recycling plants, code and category of the samples.

\begin{tabular}{llll}
\hline Recycling plant & & Sample code & Category \\
\hline Name & Acronym & & \\
\hline AMBILEI & AMB & AMB-c & C \\
& & AMB-m & M \\
ARVELA & ARV & ARV & M \\
RETRIA & RTR & RTR & M \\
S.G.R. & SGR & SGR\#1 & M \\
TRINOVO & TRI & SGR\#2 & M \\
VALNOR & VAL & TRI & VAL \\
VIMAJAS & VIM & VIM\#1 & M \\
& & VIM\#2 & M \\
\hline
\end{tabular}

C - Aggregates from concrete $\mathrm{M}$ - Aggregates from mixed CDW. 
Table 2

Summary of the processing procedures and final output of each plant.

\begin{tabular}{|c|c|c|c|c|c|c|c|c|c|}
\hline Plant & AMB & ARV & RTR & SGR\#1 & SGR\#2 & TRI & VAL & VIM\#1 & VIM\#2 \\
\hline Product specification (mm) & $0-50$ & $0.6-32.5$ & Not available & $0-20$ & $20-40$ & $0-20$ & $10-50$ & $0-8$ & $0-38$ \\
\hline $\begin{array}{l}\text { Screen aperture before } \\
\text { crushing }(\mathrm{mm})\end{array}$ & Not present & 0.6 and 32 & 40 and 150 & Not present & & 5 and 20 & Not present & 45 & \\
\hline Type of crushing & Jaw & Hammer & Jaw & Not present & & Hammer & Jaw & Hammer & \\
\hline $\begin{array}{l}\text { Screen aperture after } \\
\text { crushing (mm) }\end{array}$ & No & 0.6 and 32.5 & No & 20 and 40 & & 20 & 10 and 50 & 8 and 38 & \\
\hline
\end{tabular}

since it would be related to the geological resources and construction technologies used in the area.

Knowledge of the aggregates' properties is extremely important to concrete production since its characteristics depend directly on the quality of the aggregates (Coutinho, 1997). The EN 12620:2008 standard establishes the requirements of the aggregates used in concrete production. An experimental programme to determine the properties specified in that standard was thus devised. The mineralogical composition was obtained by X-Ray diffraction (DRX) and X-Ray fluorescence (FRX). In addition, a manual separation of the visible constituents of the FRA was performed for macroscopic characterization of the samples.

\section{Experimental programme}

Ten samples were collected from seven Portuguese CDW recycling plants (Fig. 1). They were selected in order to represent various geographical areas, implying different construction materials and processes, and geological backgrounds, as well as a variety of processing procedures. The material collected consisted of the output of the plants, commercially designated as quarry-run, all-in material, or tout-venant.

Two recycling plants (SGR and Vimajas) yield two products that contain material smaller than $4 \mathrm{~mm}$, which were both sampled. The Ambilei plant processes separately CDW made mostly of concrete and $\mathrm{CDW}$ that is a mixture of concrete and ceramics. Both products were sampled (AMB-c and AMB-m).

Table 1 gives the code for each sample and its category. The processing diagrams are different, i.e. some are more complex and others involve only a few operations. All plants have sorting and most perform fragmentation and sieving. The diagrams were examined and the most important characteristics were extracted. Table 2 summarizes the main processing characteristics and the final outputs of each plant.

The mass of the sample to be collected should be determined according to the theory of Gy (1979). As Angulo (2000) showed, to guarantee representativeness, due to the large size of the blocks appearing in the CDW stream, a huge sample of at least $1000 \mathrm{~kg}$ would be needed. Furthermore, due to the time varying characteristics of this stream of material, the sampling would have to take months, and the conclusions of any study would be valid for a limited interval of time. In view of the aim of the present study all this effort would not be justified, and therefore a large sample was

Table 3

Summary of the physical tests performed and corresponding standards.

\begin{tabular}{lll}
\hline & Test & Procedure \\
\hline Physical tests & Size distribution & EN 933-1 \\
& Moisture content & Oven drying \\
& Density & EN 1097-6 \\
& Water absorption & EN 1097-6 \\
& Bulk density & EN 1097-3 \\
& Void content & EN 1097-3 \\
& Fines content & EN 933-9 \\
& Macroscopic composition & Manual separation \\
\hline
\end{tabular}

collected corresponding to one day of plant operation. The sample was divided by quartering until a quantity of $-4 \mathrm{~mm}$ fraction of about $50 \mathrm{~kg}$, the quantity needed for the experimentation, could be produced. The size distribution of each of the whole samples collected was firstly analysed and then the fraction below $4 \mathrm{~mm}$ was separated from the rest by screening in the laboratory. After this operation, the resulting weight of the samples varied between about 40 and $70 \mathrm{~kg}$. The subsequent studies were performed only on this fraction.

The mineralogical composition was determined by X-Ray diffraction (DRX) and X-Ray fluorescence (FRX). The 1-4 mm fraction was separated into its constituents manually.

The various tests to be performed were defined, classified in physical and chemical terms, based on the EN 12620:2008 standard (aggregates for concrete). The physical tests were to determine the water content, density, water absorption, bulk density and void content.

\subsection{Mineralogical composition}

The mineralogical composition was determined by X-Ray diffraction (DRX) and X-Ray fluorescence (FRX). These analyses were performed in a semi-quantitative mode, based on standard results. The DRX results are standardized considering the greatest reflection of the main mineral phases identified: quartz, calcite, Kfeldspar, sodium feldspar, muscovite/illite and gypsum. Amorphous materials or other crystalline phases, such as hematite, portlandite, calcium and/or aluminium silicates, are not identified in this study because their reflections are usually low. The samples were also dissolved in $37 \%$ hydrochloric acid $(\mathrm{HCl})$ to determine the content of carbonates and other fractions soluble in $\mathrm{HCl}$.

\subsection{Physical properties determination}

Size distribution is one of the most important properties in aggregates since it affects concrete's compacity and, consequently, all

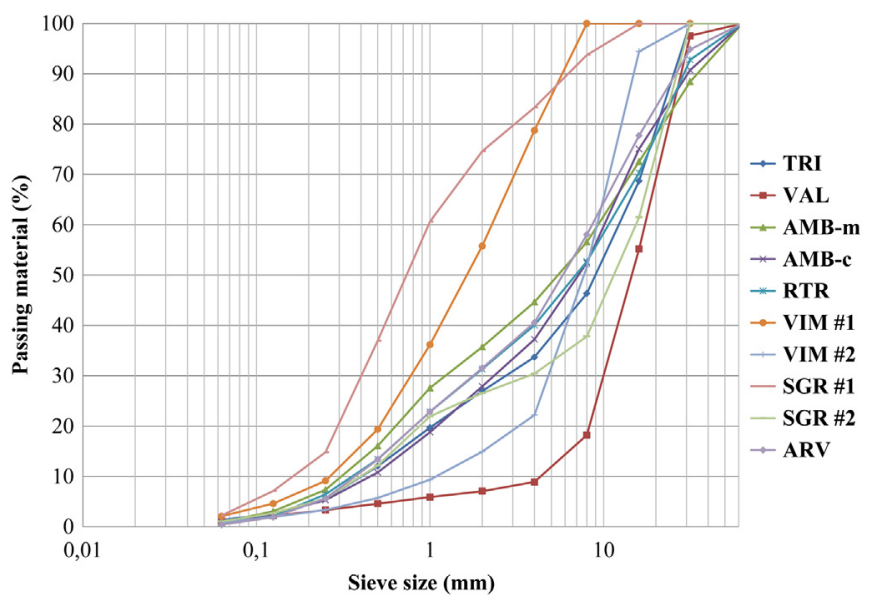

Fig. 2. Size distributions. 
Table 4

Results of the chemical and mineralogical analyses by DRX and FRX.

\begin{tabular}{|c|c|c|c|c|c|c|c|c|c|c|c|}
\hline & Plant & TRI & VAL & AMB-m & AMB-c & ARV & VIM\#1 & VIM\#2 & SGR\#1 & SGR\#2 & RTR \\
\hline $\begin{array}{l}\text { Soluble fraction (wt\% of } \\
\text { fraction } 0-4 \mathrm{~mm})\end{array}$ & & 37 & 18 & 30 & 37 & 39 & 32 & 36 & 22 & 17 & 21 \\
\hline $\begin{array}{l}\text { Fraction minus } 63 \mu \mathrm{m} \text { (wt\% of } \\
\quad \text { fraction } 0-4 \mathrm{~mm} \text { ) }\end{array}$ & & 8.2 & 10.4 & 7.9 & 4.1 & 8.1 & 5.5 & 6.3 & 5.7 & 4.8 & 13 \\
\hline Mineralogical analysis & Muscovite/Illite & 0.9 & 7.7 & 0.5 & 1 & 0.2 & 0.5 & 0.6 & 0.7 & 0.4 & 6.1 \\
\hline Fraction $0-4 \mathrm{~mm}$ & Gypsum & 0.2 & 0.1 & 0.4 & 0.2 & 0.1 & 0.2 & 0.1 & 0.8 & 0.4 & 0 \\
\hline Normalized XRD indicators & Quartz & 76 & 52.4 & 79.2 & 70.5 & 73.7 & 66 & 63.8 & 74.7 & 86.3 & 68.8 \\
\hline \multirow{5}{*}{$\begin{array}{l}\text { (\% intensity of characteristic } \\
\text { mineral reflections) }\end{array}$} & K-Feldspar (Fk) & 1 & 24.5 & 3.1 & 7.5 & 1.6 & 7.2 & 8.8 & 9.2 & 4.4 & 11 \\
\hline & $\mathrm{Na}$-Feldspar (NaF) & 1.7 & 10.6 & 0.6 & 2.6 & 0.2 & 5.3 & 1.6 & 2.2 & 3 & 8.5 \\
\hline & Calcite & 20.3 & 4.7 & 16.2 & 18.2 & 24.1 & 20.9 & 25.1 & 12.4 & 5.5 & 5.6 \\
\hline & $\mathrm{Qz} / \mathrm{c}$ & 3.7 & 11 & 4.9 & 3.9 & 3.1 & 3.2 & 2.5 & 6 & 15.6 & 12.3 \\
\hline & $(\mathrm{Qz}+\mathrm{KF}+\mathrm{NaF}) / \mathrm{c}$ & 3.9 & 18.4 & 5.1 & 4.4 & 3.1 & 3.8 & 2.9 & 6.9 & 16.9 & 15.8 \\
\hline Mineralogical analysis & Muscovite/Illite & 1.3 & 4.7 & 1.3 & 1.6 & 0.8 & 2.5 & 1.3 & 1.3 & 0.3 & 11.1 \\
\hline Fraction minus $63 \mu \mathrm{m}(\%)$ & Gypsum & 0 & 0 & 0 & 0 & 0 & 1.1 & 0.7 & 3.6 & 3.3 & 0 \\
\hline Normalized XRD indicators & Quartz (Qz) & 55.1 & 47.3 & 50.7 & 48 & 57 & 50.4 & 43.7 & 47.5 & 68.7 & 43.2 \\
\hline \multirow{5}{*}{$\begin{array}{l}\text { (\% intensity of diagnostic } \\
\text { mineral reflections) }\end{array}$} & K-Feldspar (Fk) & 5.8 & 7.3 & 5.6 & 4.8 & 2.7 & 8.7 & 3.6 & 4.1 & 1.2 & 9.7 \\
\hline & Na-Feldspar (NaF) & 1 & 8.4 & 0.8 & 1.8 & 1.7 & 2.4 & 2.4 & 4.3 & 3 & 16.5 \\
\hline & Calcite (c) & 36.9 & 32.2 & 41.6 & 43.8 & 37.8 & 35 & 48.3 & 39.2 & 23.5 & 19.5 \\
\hline & $\mathrm{Qz} / \mathrm{c}$ & 1.5 & 1.5 & 1.2 & 1.1 & 1.5 & 1.4 & 0.9 & 1.2 & 2.9 & 2.2 \\
\hline & $(\mathrm{Qz}+\mathrm{KF}+\mathrm{NaF}) / \mathrm{c}$ & 1.7 & 2 & 1.4 & 1.2 & 1.6 & 1.8 & 1 & 1.4 & 3.1 & 3.6 \\
\hline Chemical analysis & $\mathrm{Fe}$ & 56.3 & 88.6 & 36.3 & 34.8 & 48.4 & 71.4 & 42.8 & 57.6 & 69.8 & 81.8 \\
\hline Fraction $0-4 \mathrm{~mm}$ & $\mathrm{Mn}$ & 1.02 & 1.38 & 0.83 & 0.54 & 0.67 & 1.1 & 0.57 & 0.77 & 0.61 & 0.92 \\
\hline Normalized XRF indicators & $\mathrm{Ti}$ & 2.13 & 3.03 & 2.44 & 1.31 & 2.02 & 3.18 & 1.6 & 3.26 & 2.36 & 3.36 \\
\hline Ratio of elemental & $\mathrm{Ca}$ & 225.9 & 103.7 & 219.6 & 256.7 & 254.2 & 200.5 & 111.7 & 157.7 & 94.6 & 81.1 \\
\hline \multirow[t]{7}{*}{$\mathrm{k} \alpha$ intensity related to $\mathrm{Si}$} & $\mathrm{K}$ & 13.7 & 23.3 & 13.9 & 11.5 & 8.2 & 17.5 & 7.4 & 14.9 & 11.4 & 26.7 \\
\hline & $\mathrm{Mg}$ & 0.53 & 1.25 & 0.52 & 0.36 & 0.46 & 0.49 & 0.18 & 0.43 & 0.37 & 0.38 \\
\hline & $\mathrm{Na}$ & 0.4 & 0.28 & 0.2 & 0.3 & 0.25 & 0.5 & 0.18 & 0.54 & 0.63 & 0 \\
\hline & $\mathrm{Cl}$ & 4.2 & 1.62 & 3.9 & 1.6 & 2.04 & 2.51 & 0.96 & 7.9 & 5.2 & 1.91 \\
\hline & $S$ & 31.9 & 37.9 & 37.5 & 37.4 & 20.2 & 35.3 & 14.8 & 37.4 & 42.5 & 44.0 \\
\hline & $\mathrm{Si}$ & 6.52 & 7.72 & 5.05 & 4.57 & 5.05 & 8.24 & 3.83 & 5.12 & 4.84 & 10.59 \\
\hline & $\mathrm{Al}$ & 0.2 & 0.9 & 0.2 & 0.1 & 0.2 & 0.4 & 0.4 & 0.4 & 0.7 & 1 \\
\hline
\end{tabular}

its properties (Neville, 1996). To evaluate these properties the procedure from the EN 933-1 (CEN, 1997) standard was used, with a slight change. Contrary to the standard's specification it was decided not to wash the aggregates before the grading analysis, since FRA have a large fraction of very fine material (size below $0.063 \mathrm{~mm}$ ) that would be removed by washing. This was the only test where the whole samples collected from the recycling plants were used.

Afterwards the material was separated into two fractions, above and below $4 \mathrm{~mm}$, and the latter was used in the remaining tests. The water content was determined by drying in an oven.

The EN 1097-6 (CEN, 2000) standard was used to determine the density and water absorption of the FRA. Knowing the density is important since it is more accurate to dose the materials by weight than by volume (Evangelista and de Brito, 2007). The water absorption is markedly higher in FRA than in FNA, which highlights the importance of measuring it.

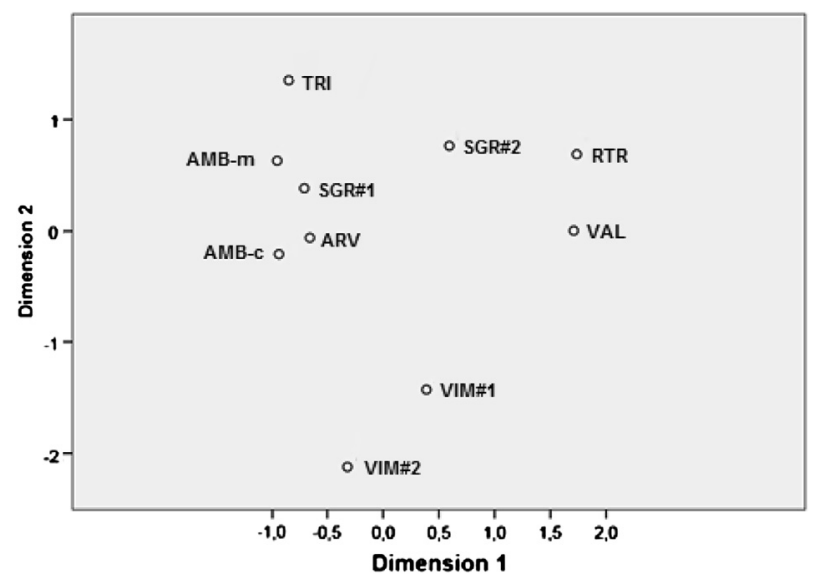

Fig. 3. Aggregates grouped in terms of chemical and mineralogical characteristics.
The bulk density was determined according to the specifications of the 1097-3 (CEN, 1998) standard. The void content was obtained from the previous properties.

According to the EN 12620 standard the fines content is the percentage of aggregate that passes the $0.063 \mathrm{~mm}$ sieve. The fines particles can be clays (less than $2 \mathrm{~mm}$ ) or silt and stone powder from crushing (between $2 \mu \mathrm{m}$ and $60 \mu \mathrm{m}$ ).

The EN 933-9 (CEN, 2009) standard describes the procedure of the methylene blue test, used to determine the fines content in terms of clay particles.

A manual separation into the following classes with the aid of a magnifying glass of the $1-4 \mathrm{~mm}$ fraction was also performed: minerals (including cementitious mass), bricks and light materials (mostly wood and plastic). The separation was performed for the fraction above $1 \mathrm{~mm}$ since it is very hard to distinguish the composition of smaller particles.

A summary of the physical tests performed and the relevant standard used is presented in Table 3.

\subsection{Chemical properties determination}

The chemical tests were carried out according to the procedures of the EN 1744-1:2009 standard. The water soluble chlorides content, water and acid soluble sulphates content, the sulphur content, the light contaminants content, the humus content and the aggregate's water solubility were determined.

\section{Results}

\subsection{Size distribution and mineralogical composition}

Fig. 2 shows the results of the size distribution analysis performed on all the samples from the recycling plants. It was found that for most plants this distribution follows the pattern of a 
Table 5

Results of the manual separation.

\begin{tabular}{|c|c|c|c|c|c|c|c|c|c|c|}
\hline Sample & AMB-c & AMB-m & ARV & RTR & SGR\#1 & SGR\#2 & TRI & VAL & VIM\#1 & VIM\#2 \\
\hline Minerals (wt\%) & 99.0 & 92.8 & 98.7 & 94.1 & 94.4 & 92.7 & 93.3 & 92.6 & 89.9 & 85.6 \\
\hline Bricks (wt\%) & 0.7 & 6.8 & 1.0 & 5.2 & 4.1 & 5.6 & 5.6 & 7.2 & 8.6 & 13.5 \\
\hline Others (wt\%) & 0.1 & 0.4 & 0.3 & 0.2 & 0.5 & 0.8 & 0.4 & 0.2 & 0.1 & 0.1 \\
\hline Total (wt\%) & 100.0 & 100.0 & 100.0 & 100.0 & 100.0 & 100.0 & 100.0 & 100.0 & 100.0 & 100.0 \\
\hline
\end{tabular}

quarry-run aggregate, i.e. the percentage of particles in each fraction is similar to the others.

According to the EN 206-1 (CEN, 2000) standard this type of aggregate can only be used in concrete with a compressive strength class of C12/15 or lower. Therefore if these aggregates are used straight from the recycling plants, they can only be used in blinding concrete or concrete with low structural demands. However postprocessing that selects only one size range of the particles, preferably the one with the best characteristics, may allow the aggregates to be incorporated in better quality concrete compositions.

Table 4 gives the results of the DRX and FRX analyses. The results were analysed so as to understand how this significant set of data interacts between the various samples. In Fig. 3 each sample is represented by a single point on a normalized plan. The points will be closer when the chemical and mineralogical characteristics are similar. Fig. 3 shows that the samples are grouped in three clusters of similar characteristics.

TRI, AMB-b, ARV and SGR\#1 are the samples that exhibit the greatest solubility in hydrochloric acid and a high calcite content, which shows that they are made mostly of limestone. Table 4 shows that the quartz content is high in all the recycling plants of this group. Unlike the other samples in the group SGR\#1 and AMB-m show high gypsum content. This is corroborated by the chemical analysis of the samples with the highest sulphur content.

The SGR\#2 sample, even though they have the same solubility level and similar ratios to the VAL and RTR samples, cannot be included in the same group as them, since it does not show traces of minerals that prove its granite origins (the muscovite and feldspars contents are very low). This sample, coming from the second sieve, has a different mineralogical composition from that of the first sieve, which has lower calcite and higher quartz contents.

It is interesting to note that in all samples the calcite content of the fraction below $0.063 \mathrm{~mm}$ increases, relative to the whole sample. This indicates that limestone tends to concentrate in the smaller size fraction and also explains the loss of calcite from the SGR\#1 to SGR\#2 samples. The VIM\#1 and VIM\#2 samples make up the third group. Their high calcite and acid soluble contents mean they may also be considered calcareous (in keeping with the type of rock of the region). However, they differ from the first group in that they contain intermediate feldspars.

The results of the manual separation of the 1-4 mm fraction are shown in Table 5 . The mortar and cementitious particles were included in the "minerals" category while "others" comprises the wood, plastic and glass particles. This class is of little relevance in any of the plants, averaging $0.31 \%$ which shows that all the plants have an efficient separation process. This is a similar figure to that obtained by Bianchini et al. (2005). The minerals category is the most relevant in all plants, and the AMB-c sample has the highest content since it results from the utilization of waste made mostly of concrete. The brick content is similar in the various samples, with an average of $5.8 \%$.

\subsection{Physical properties of the aggregates}

Table 6 displays the test results for the aggregates' physical properties. Apart from the water absorption and fines content, the characteristics presented do not influence concrete production. The maximum allowable values of these two properties for concrete production are given in the table.

The water content differs greatly from plant to plant, with an average of $4.48 \%$ and a variation coefficient of $54.75 \%$. The various densities are presented in Fig. 4.

Particle density normally has no practical application in the formulation and production of concrete, since it only indicates the density of the material that makes up the particles, which is a function of the original rock. Fig. 4 shows a high scatter of this parameter between the samples, in agreement with the results of other researchers (Angulo, 2000; Angulo, 2005; Leite, 2001). The average for oven-dry density is $2281.8 \mathrm{~kg} / \mathrm{m}^{3}$, which agrees with previous research (Evangelista and de Brito, 2007; Leite, 2001; Khatib, 2005; Dessy et al., 1998) that proved a clear decrease of this parameter compared with fine natural aggregates. Evangelista and de Brito (2007) found an oven-dry density for fine natural aggregates of $2544 \mathrm{~kg} / \mathrm{m}^{3}, 11.5 \%$ above the result obtained here for FRA.

The difference between oven-dry density and the saturated surface-dry density defines the water-retaining capacity of the particles and therefore their water absorption. FRA not only have much higher water absorption than FNA (measured by Evangelista and de Brito (2007) as $0.8 \%$ ), they also have significant scatter, which in this study reaches a standard deviation of $25.6 \%$. FRA water absorption found by other researchers ranges from 5.5\% (Müller and Winkler, 1998) to 16.8\% (Barra and Vazquez, 1998).

Bearing in mind these two issues, the mixing water volume must be defined exactly if these aggregates are used to make concrete. According to Gonçalves and de Brito (2010) the water absorption code limit imposed on aggregates for use in concrete is

Table 6

Results of the physical tests.

\begin{tabular}{|c|c|c|c|c|c|c|c|c|c|c|c|}
\hline Sample & $\begin{array}{l}\text { Maximum } \\
\text { value }\end{array}$ & AMB-c & AMB-m & ARV & RTR & SGR\#1 & SGR\#2 & TRI & VAL & VIM\#1 & VIM\#2 \\
\hline Water content (wt\%) & - & 10.06 & 4.71 & 2.16 & 1.96 & 3.70 & 2.06 & 5.58 & 3.53 & 6.01 & 5.02 \\
\hline Particles density $\left(\mathrm{kg} / \mathrm{m}^{3}\right)$ & - & 2685 & 2601 & 2646 & 2573 & 2638 & 2647 & 2649 & 2653 & 2644 & 3059 \\
\hline Oven-dry density $\left(\mathrm{kg} / \mathrm{m}^{3}\right)$ & - & 2225 & 2340 & 2191 & 2284 & 2321 & 2382 & 2138 & 2358 & 2230 & 2671 \\
\hline Saturated surface-dry density $\left(\mathrm{kg} / \mathrm{m}^{3}\right)$ & - & 2396 & 2441 & 2363 & 2396 & 2441 & 2482 & 2331 & 2469 & 2387 & 2798 \\
\hline Bulk density $\left(\mathrm{kg} / \mathrm{m}^{3}\right)$ & - & 1354 & 1442 & 1332 & 1256 & 1383 & 1286 & 1306 & 1387 & 1291 & 1321 \\
\hline Void content (v\%) & - & 39.1 & 38.4 & 39.2 & 45.0 & 40.4 & 46.0 & 38.9 & 41.2 & 42.1 & 50.5 \\
\hline Water content (wt\%) & 7 & 7.1 & 4.1 & 7.3 & 4.7 & 4.9 & 4.0 & 8.3 & 4.5 & 6.6 & 5.5 \\
\hline Fines content (g/kg) & 2 & 0.73 & 1.11 & 1.29 & 1.40 & 3.08 & 3.20 & 1.18 & 1.11 & 3.37 & 2.48 \\
\hline
\end{tabular}




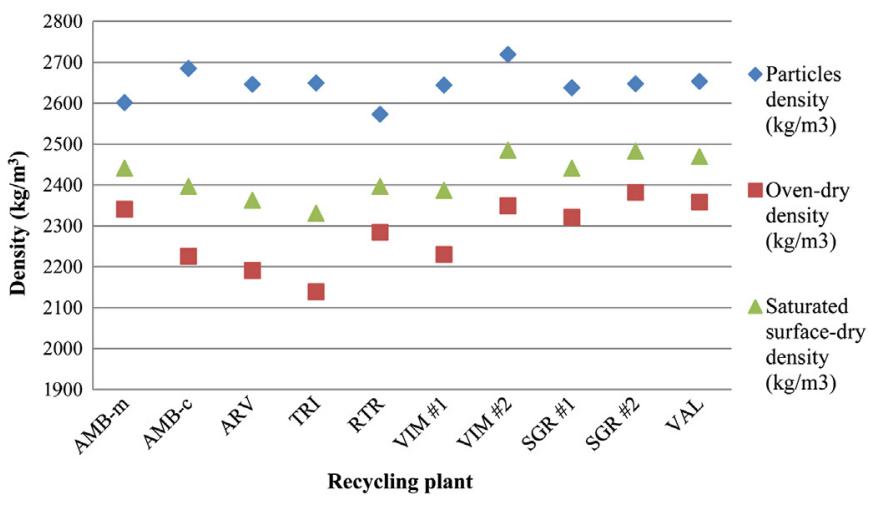

Fig. 4. Density of aggregates.

$7 \%$, which precludes the use of samples AMB-b, ARV and TRI in concrete. However Evangelista and de Brito (2007) produced concrete with incorporation of FRA and water absorption over 13\% whose performance can be considered acceptable for current applications.

Concerning the fines content (below $0.063 \mathrm{~mm}$ ), the methylene blue test was performed and the results are found in Table 5. They indicate high values of clays in all samples, with SGR\#1, SGR\#2, VIM\#1 and VIM\#2 exceeding the $2 \mathrm{~g} / \mathrm{kg}$ limit imposed by European Technical Commission 154. The average of all the samples is $1.9 \mathrm{~g} /$ $\mathrm{kg}$. The average bulk density of all aggregates studied is $1335.8 \mathrm{~kg} /$ $\mathrm{m}^{3}$, while the average void content is $42.08 \%$.

\subsection{Chemical properties of the aggregates}

The results of the chemical tests are presented in Table 7, which also contains the corresponding maximum admissible values for using aggregates in concrete production, according to EN 12620. This standard establishes three categories of aggregates, depending on whether their solubility in acid is below $0.2 \%$, over $0.8 \%$ or between these two limits.

The humus content test is only qualitative for the existence of organic matter in the sample, and since it was negative for all samples it is not included in Table 7. The EN 12620 standard establishes that the chloride content must be taken into account when formulating the concrete's composition. The limit of incorporation in concrete is $1 \%$ relative to the cement weight. Based on Table 7 it is concluded that none of the samples exceeds the chlorides threshold.

Sulphates tend to react with alumina from the aggregates or the cement in the presence of an oversaturated solution of sodium hydroxide, forming ettringite in an expansive reaction. This type of reaction inside concrete leads to delamination of the reinforcement cover and consequent decrease of the structure's durability. But some sulphur compounds may also oxidize inside concrete and produce sulphates. The presence of gypsum in the fine recycled aggregates also increases the inbuilt presence of sulphates.

The EN 12620 standard indicates that the sulphate content must be determined in acid while other standards (NBR 7211:2004,
RILEM, TC 121-DGR, 2004) state that it must be measured relative to the percentage soluble in water. However, this latter procedure does not consider sulphates from gypsum and therefore it was decided to perform both tests, whose results are presented in Table 7.

EN 12620 establishes that the aggregates with acid soluble sulphate content higher than $0.8 \%$ by mass cannot be used to produce reinforced concrete. Based only on this condition, most of the samples could be used in concrete. As for the water soluble sulphate content, the limit set by the Brazilian standard and by RILEM is $1 \%$, i.e. all the samples comply with that limit. Therefore for the same parameter it is found that some of the samples comply with the limit in terms of water soluble sulphate content but their use in concrete would be detrimental since the sulphates from gypsum were not considered. It is thus recommended to only use the water soluble sulphate content test when there are no traces of gypsum, and in other circumstances opt for the acid soluble sulphates content test because it detects the presence of gypsum.

It is important to control the sulphur content of the aggregates because they react with oxygen and to form sulphates, leading to the problems already described. The EN 1744-1:2009 standard specifies that the sulphur content must remain below $1 \%$ in mass for aggregates, except for air-cooled blast furnace slag. Table 7 shows that none of the samples exceeds this limit.

The proportion of light organic contaminants is determined according to the EN 1744-1:2009 standard. For fine aggregates the maximum value accepted is $0.5 \%$ by mass. If the finishing of the concrete's surface is of special concern this limit is reduced to $0.25 \%$. Only the VIM\# 1 sample has contaminant content below $0.5 \%$, but it is higher than $0.25 \%$ (Table 7 ).

Solubility in water provides an early indication of the mass loss of the aggregates when mixed with water. This is an undesirable characteristic since there may be elements that jeopardize concrete's performance at the chemical level in the part of the aggregate's mass that is lost. According to Dhir et al. (2001) the BS EN 1744 standard mentions three categories: no requirements, solubility below $10 \%$ of the sample's mass and over $10 \%$. Table 7 shows that the maximum solubility of any of the samples is $3.4 \%$.

\section{Discussion}

Analysing Tables 6 and 7 one sees that none of the samples collected in the various plants has all characteristics within the limits imposed in EN 12620, to allow incorporation in concrete. Indeed, AMB-m, RTR and VAL did not comply with any of the requisites and all the other samples failed to comply with at least two requisites. The light contaminants content is exceeded by all samples, if the $0.25 \%$ limit is applied. The other property that differs greatly relative to fine natural aggregates is the presence of fines detrimental to concrete, namely clays.

As for the chemical analyses the aggregates proved to have no use limitations concerning the chlorides content. When the sulphate content is measured in terms of solubility in water all aggregates comply with the limit imposed by the Brazilian standard and the RILEM specification (there are no Portuguese or European code specifications for this). But when it comes to sulphates soluble

Table 7

Results of the chemical tests.

\begin{tabular}{|c|c|c|c|c|c|c|c|c|c|}
\hline Sample & Maximum value & AMB-b & AMB-m & ARV & RTR & SGR\#1 & TRI & VAL & VIM\#1 \\
\hline Water soluble chlorides (\%) & 0.01 & $<0.01$ & 0.01 & $<0.01$ & $<0.01$ & 0.01 & 0.01 & 0.01 & 0.01 \\
\hline Water soluble sulphates (\%) & 1 & 0.03 & 0.14 & 0.11 & 0.18 & 0.25 & 0.14 & 0.13 & 0.16 \\
\hline Acid soluble sulphates $\left(\mathrm{SO}_{3} \%\right)$ & $0.2 / 0.8$ & 0.32 & 0.6 & 0.41 & 0.77 & 1.53 & 0.77 & 0.27 & 0.91 \\
\hline Total sulphur content (\%) & 1 & 0.06 & 0.11 & 0.1 & 0.34 & 0.6 & 0.29 & 0.03 & 0.00 \\
\hline Light contaminants (\%) & 0.25 & 1.20 & 1.60 & 0.60 & 17.10 & 2.30 & 3.10 & 1.00 & 0.28 \\
\hline Water solubility (\%) & 10 & 2.0 & 1.7 & 1.1 & 1.6 & 1.9 & 3.4 & 2.7 & 2.7 \\
\hline
\end{tabular}


in acid, for which a limit is imposed by EN 1744-1:2009, some samples do not comply with that limit. It was found that most sulphates present in these aggregates come from gypsum and that the VIM and SGR plants process more gypsum waste than the others. The FRA do not fulfil the requirements for use in concrete mostly because they fail in terms of: water absorption, light contaminants and detrimental fines content.

For easier interpretation of the results a correspondence analysis (CA) was performed (Greenacre, 2006). This analysis allows the description of the relationship between the various categorical variables. The input variables were the mineralogical composition of the CDW inert fraction and the main processing features, and the output variables were the physical and chemical properties of the aggregates produced.

In terms of processing procedures, once the diagrams of all the plants had been analysed it was concluded that they are all different and have various degrees of complexity. The main differences relate to the existence and type of fragmentation and whether or not sieving is done after fragmentation to eliminate the fines.

As for the physical and chemical properties, only the three properties that yielded different results in the various plants were analysed. The following classes were established for each:

- In terms of mineralogical composition: granite (Gr), limestone $(\mathrm{L})$ and limestone with feldspars $(\mathrm{L}+\mathrm{F})$;

- In terms of processing procedures, and concerning fragmentation type: crushing with jaw-crusher $(\mathrm{Cj})$, crushing with hammer-crusher $(\mathrm{Ch})$ and no crushing $(\mathrm{nC})$; and sieving after fragmentation: yes (Sc) or no (nSc);

- In terms of aggregates' physical and chemical properties, two classes were considered, according to compliance or noncompliance with concrete production requirements for water absorption ( $\mathrm{W}+$ and $\mathrm{W}-$ ), fines content $(\mathrm{F}+$ and $\mathrm{F}-$ ) and acid soluble sulphates content ( $\mathrm{S}+$ and $\mathrm{S}-$ ).

In Fig. 5, the plants and variables were both projected on the first factorial plan from CA. The plants were introduced for evaluation of their relationship with the input variables (aggregates' mineralogical composition and processing features).

The RTR and VAL plants predominantly handle CDW from granite and jaw-crushers $(\mathrm{Cj})$ are used to fragment the waste. The SGR plant stands out from the others because it does not carry out any fragmentation operations ( $\mathrm{nC}$ ) and the VIM plant handles CDW limestone with feldspars content higher than the others $(L+F)$. Additionally, the variable that reflects the existence of sieving after

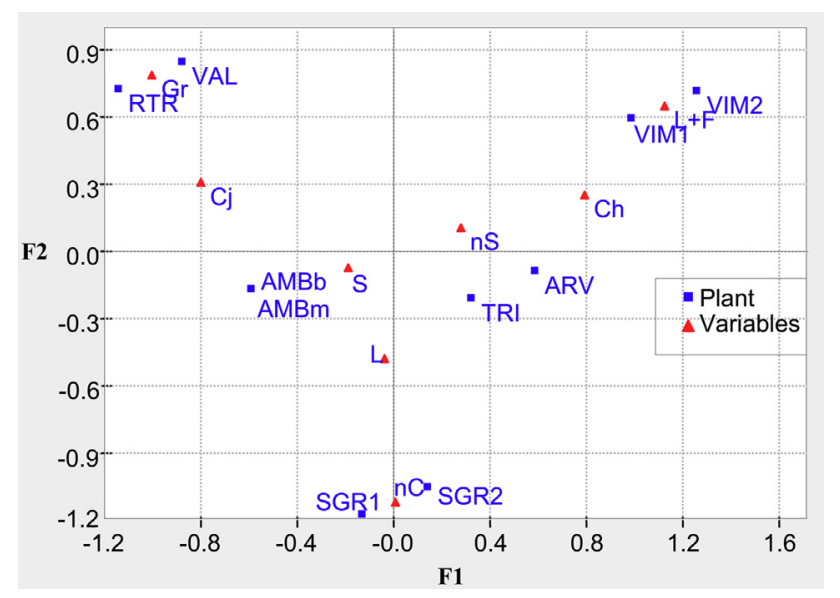

Fig. 5. Correspondence analysis. Representation of input variables and plants.

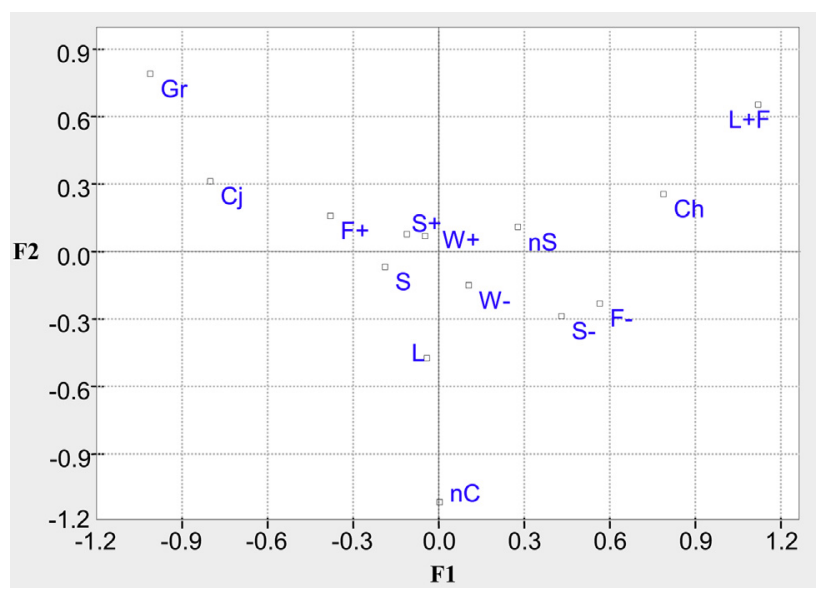

Fig. 6. Correspondence analysis. Representation of input and output variables.

fragmentation, located in the centre of the diagram, is not a significant variable, i.e. it does not explain the final results of the analysis.

This confirms that the existence of fragmentation and its type and the mineralogical composition of the aggregates are the most significant variables and that they are strongly related.

To see if the properties of the aggregates depend on the input variables, those variables were displayed as supplementary variables on the CA plot (Fig. 6) whose axes were defined by the input variables.

It was found that the high fines (clays) and acid soluble sulphates (gypsum) contents are strongly correlated with the lack of fragmentation and with the limestone with feldspars mineralogical composition. The only two samples that have fines content above the threshold (Table 6) are the finer products from the plants with two differently sized outputs (plants VIM and SGR).

Furthermore, there is no noticeable influence of either the mineralogical composition or the selected processing features on the water absorption of the aggregates. However, in the particular case of the AMB plant that handles separately the mixed CDW and CDW made mostly of concrete, only the latter has water absorption higher than the limit, probably because it has significant cement content. A final sieving after fragmentation is not correlated with any of the remaining variables, including the physical and chemical properties.

Some of the problems described, and others such as the potential existence of heavy metals, may be solved by using mining separation techniques, as suggested by Xing and Hendricks (2006).

\section{Conclusions}

In this work the physical and chemical properties relevant for the incorporation of aggregates in concrete were determined in 10 samples of fine aggregates from CDW obtained from seven Portuguese plants located in various geographical and geological regions. These properties were related to the mineralogical composition and the processing procedures the aggregates underwent.

It was found that the mineralogical composition of the fine recycled aggregates reflects the geological environs of the recycling plant location, showing that these plants predominantly process CDW containing materials mined in their regions.

Taking into consideration the limit values usually applied to the use of natural aggregates for concrete production, it was found that any of the samples could be used in terms of chloride content, water soluble sulphate content, aggregates' solubility in water, humus content and total sulphur content. However, regardless of the mineralogical composition and the processing diagram, strictly 
speaking none of the samples could be used in concrete production because of their excessive light contaminants content. Since none of the CDW recycling plants presently operating in Portugal uses any high-tech separation equipment, this conclusion should be viewed with some caution.

Three other properties that were determined, water absorption, fines content and acid soluble sulphate content, exhibited values that would prevent some of the samples from being used to produce concrete. In this case the suitability is strongly dependent on the mineralogical composition, with the granitic aggregates having the best characteristics.

The compounds that negatively affect the characteristics of the aggregates are gypsum, related to the acid soluble sulphate content, clays, which give a high fines content, and cement, related to greater water absorption. They may prevent the use of these aggregates in concrete and are concentrated in the fraction below $0.063 \mathrm{~mm}$. Therefore washing the aggregates to eliminate the fraction below $0.063 \mathrm{~mm}$ before using them in concrete production should substantially improve their quality. Further research is needed to understand whether the negative impacts of this operation balance the positive effects of preventing the $0.063-4 \mathrm{~mm}$ CDW fraction from being dumped, as is the rule nowadays. The fraction below $0.063 \mathrm{~mm}$ presents yet another challenge to research and the mining and construction industries.

\section{Acknowledgements}

The authors wish to thank FCT (Project FCT PTDC/ECM/108682/ 2008) for financial support and Professor Manuel Pereira from the museum of mineralogy and Geology of IST for performing the mineralogical and chemical analyses. They also thank ICIST (Instituto de Engenharia de Estruturas, Território e Construção), CERENA (Centro de Recursos Naturais e Ambiente), IST and the Technical University of Lisbon.

\section{References}

Amorim, P., de Brito, J., Evangelista, L., 2012. Concrete made with coarse concrete aggregate: influence of curing on durability. ACI Mater. J. 109 (2), 195-204.

Angulo, S., 2000. Variability of Coarse Recycled Aggregates From Construction and Demolition Waste. Masters Dissertation in Engineering, Polytechnic School of the São Paulo University, São Paulo, Brazil, 172 pp. (in Portuguese).

Angulo, S., 2005. Characterization of Recycled Aggregates From Construction and Demolition Waste and Influence of Their Characteristics on the Performance of Concrete. PhD in Civil Engineering, São Paulo University, São Paulo, Brazil, 236 pp. (in Portuguese).

Angulo, S., Ulsen, C., John, V., Kahn, H., Cincotto, M., 2009. Chemical-mineralogical characterization of C\&D waste recycled aggregates from São Paulo, Brazil. Waste Manage. 29 (2), 721-730.

Austen, M., Hattam, C., Lowe's, S., Marge, S., Richardson, K., 2009. Quantifying and Valuing the Impacts of Marine Aggregate Extraction on Ecosystem Goods and Services. Marine Aggregate Levy Sustainability Fund, Plymouth, UK. MEPF Ref. \# 08/P77, $72 \mathrm{p}$.

Barra, M., Vazquez, E., 1998. Properties of concretes with recycled aggregates: influence of properties of the aggregates and their interpretation. In: Sustainable Construc tion: Use of Recycled Concrete Aggregate. Thomas Telford, London, UK, pp. 19-30.

Bianchini, G., Marrocchino, E., Tassinari, R., Vaccaro, C., 2005. Recycling of construction and demolition waste: a chemical-mineralogical appraisal. Waste Manage. 25 (2), 149-159.

Blengini, G.A., Garbarino, E., 2010. Resources and waste management in Turin (Italy): the role of recycled aggregates in the sustainable supply mix. J. Clean. Prod. 18 (10-11), 1021-1030.

Blengini, G.A. Garbarino, E., Solar, S., Shields, D., Hámor, T. Vinai, R., Agioutantis, Z 2012. Life cycle assessment guidelines for the sustainable production and recycling of aggregates: the sustainable aggregates resource management project (SARMa). J. Clean. Prod. 27, 177-181.

CEN EN 1097-3, 1998. Tests for Mechanical and Physical Properties of Aggregates Part 3: Determination of Loose Bulk Density and Voids. Brussels, Belgium.

CEN EN 1097-6, 2000. Tests for Mechanical and Physical Properties of Aggregates Part 6: Determination of Particle Density and Water Absorption. Brussels, Belgium. CEN EN 12620, 2008. Aggregates for Concrete, Brussels, Belgium.

CEN EN 1744-1, 2009. Tests for Chemical Properties of Aggregates - Part 1: Chemical Analysis, Brussels, Belgium.
CEN EN 206-1, 2000. Concrete: Specification, Performance, Production and Conformity, Part 1. Brussels, Belgium.

CEN EN 933-1, 1997. Tests for Geometrical Properties of Aggregates - Part 1: Determination of Particle Size Distribution - Sieving Method. Brussels, Belgium. CEN EN 933-9, 2009. Tests for Geometrical Properties of Aggregates. Part 9: Assessment of Fines - Methylene Blue Test, Brussels, Belgium.

Coelho, A., de Brito, J., 2012a. Economic viability analysis of a construction and demolition waste plant in Portugal - part I: location, materials, technology and economic analysis. J. Clean. Prod. 39 (1), 338-352.

Coelho, A., de Brito, J., 2012b. Economic viability analysis of a construction and demolition waste plant in Portugal - part II: economic sensitivity analysis. J. Clean. Prod. 39 (1), 329-337.

Coutinho, A., 1997. Production and Properties of Concrete, vol. I. LNEC, Lisbon, Portugal, 401 p. (in Portuguese)

Dessy, P., Badalucco, C., Bignami, F.C., 1998. Analysis of performances of concrete components made with recycled aggregates. In: Materials and Technologies for Sustainable Construction - CIB World Building Congress, Gävle, Sweden, pp. 149-156.

Dhir, R., Limbachiya, C., Beggs, A., 2001. Resolving Application Issues with the Use of Recycled Concrete Aggregate. Concrete Technology Unit, Report CTU/1601. University of Dundee, UK, $171 \mathrm{p}$.

Evangelista, L., de Brito, J., 2007. Mechanical behaviour of concrete made with fine recycled concrete aggregates. Cement Concrete Comp. 29 (5), 397-401.

Evangelista, L., de Brito, J., 2010. Durability performance of concrete made with fine recycled concrete aggregates. Cement Concrete Comp. 32 (1), 9-14.

Ferreira, L., de Brito, J., Barra, M., 2011. Influence of the pre-saturation of recycled coarse concrete aggregates on the fresh and hardened properties of concrete. Mag. Concrete Res. 63 (8), 617-627.

Fisher, C., Werge, M., 2009. EU as a Recycling Society - Present Recycling Levels of Municipal Waste and Construction \& Demolition Waste in the EU. ETC/SCP working paper 2/2009, Copenhagen, Denmark, $73 \mathrm{p}$.

Fonseca, N., de Brito, J., Evangelista, L., 2011. The influence of curing conditions on the mechanical performance of concrete made with coarse recycled concrete aggregates. Cement Concrete Comp. 33 (6), 637-643.

Gonçalves, P., de Brito, J., 2010. Recycled aggregate concrete (RAC) - comparative analysis of existing specifications. Mag. Concrete Res. 62 (5), 339-346.

Greenacre, M., 2006. Multiple Correspondence Analysis and Related Methods. Chapman \& Hall, London, UK, 581p.

Gy, P., 1979. Sampling of Particulate Materials: Theory and Practice. Elsevier Scientific Publishing Company, Amsterdam, 431p.

Khatib, J., 2005. Properties of concrete incorporating fine recycled aggregate Cement Concrete Res. 35 (4), 763-769.

Kwan, W., Ramli, M., Kam, K., Suleiman, M., 2011. Influence of the amount of recycled coarse aggregate in concrete design and durability properties. Constr. Build. Mater. 26 (1), 565-573.

Leite, M., 2001. Evaluation of the Mechanical Properties of Concrete Made With Recycled Aggregates From Construction and Demolition Waste. PhD thesis on Civil Engineering, School of Engineering, Federal University of Rio Grande do Sul, Porto Alegre, Brazil, 270 pp. (in Portuguese).

Müller, A., Winkler, A., 1998. Characteristics of processed concrete rubble. In: Sustainable Construction: Use of Recycled Concrete Aggregate. Thomas Telford, London, UK, pp. 109-119.

NBR 7211, 2004. Concrete Aggregates - Specification, Brazil (in Portuguese).

Neville, A., 1996. Properties of Concrete, fourth ed. Wiley, London, UK, 844 p.

Pereira, P., Evangelista, L., de Brito, J., 2012a. The effect of superplasticizers on the workability and compressive strength of concrete made with fine concrete aggregates. Constr. Build. Mater. 28 (1), 722-729.

Pereira, P., Evangelista, L., de Brito, J., 2012b. The effect of superplasticizers on the mechanical performance of concrete made with fine recycled concrete aggregates. Cement Concrete Comp. 34 (9), 1044-1052.

Rahal, K., 2007. Mechanical properties of concrete with recycled coarse aggregate. Build. Environ. 42 (1), 407-415.

Richardson, A., Coventry, K., Bacon, J., 2011. Freeze/thaw durability of concrete with recycled demolition aggregate compared to virgin aggregate concrete. J. Clean. Prod. 19 (2-3), 272-277.

RILEM TC 121-DRG, 2004. Specifications for concrete with recycled aggregates. Mater. Struct. 27, 557-559.

Rodrigues, F., Carvalho, T., Pereira, M., Evangelista, L., de Brito, J., 2011. Physical and chemical-mineralogical characterization of fine recycled aggregates from construction and demolition waste. In: Fray International Symposium, Cancun, Mexico, pp. 301-318.

Solyman, M., 2005. Classification of Recycled Sands and Their Applications as Fine Aggregates for Concrete and Bituminous Mixtures. PhD thesis in Engineering, University of Kassel, Kassel, Germany, 194 pp.

Tam, V., 2009. Comparing the implementation of concrete recycling in the Australian and Japanese construction industries. J. Clean. Prod. 17 (7), 688-702.

The Freedonia Group, 2012. World Construction Aggregates to 2015. Industry Study \# 2838, Cleveland, USA, 334 p..

Vieira, J., Correia, J., de Brito, J., 2011. Post-fire residual mechanical properties of concrete made with recycled concrete coarse aggregates. Cement Concrete Res. 41 (5), 533-541.

Xing, W.H., Hendricks, C., 2006. Decontamination of granular wastes by mining separation techniques. J. Clean. Prod. 14 (8), 748-753.

Zega, C., Maio, A., 2011. Use of recycled fine aggregates in concretes with durable requirements. Waste Manage. 31 (11), 2336-2340. 